\title{
Analysis of soil and vegetation patterns in semi-arid Mediterranean landscapes by way of a conceptual water balance model
}

\author{
I. Portoghese ${ }^{1}$, V. Iacobellis ${ }^{2}$, and M. Sivapalan ${ }^{3, *}$ \\ ${ }^{1}$ Istituto di Ricerca Sulle Acque, Bari, Italy \\ ${ }^{2}$ Dipartimento di Ingegneria delle Acque e Chimica, Politecnico di Bari, Italy \\ ${ }^{3}$ Centre for Water Research, The University of Western Australia, Crawley, WA, Australia \\ *now at: Dept. of Geography and Civil and Environmental Engineering, Univ. of Illinois at Urbana-Champaign, IL, USA
}

Received: 28 September 2007 - Published in Hydrol. Earth Syst. Sci. Discuss.: 19 October 2007

Revised: 16 May 2008 - Accepted: 20 May 2008 - Published: 13 June 2008

\begin{abstract}
This paper investigates the impact of various vegetation types on water balance variability in semi-arid Mediterranean landscapes, and the different strategies they may have developed to succeed in such water-limited environments. The existence of preferential associations between soil water holding capacity and vegetation species is assessed through an extensive soil geo-database focused on a study region in Southern Italy. Water balance constraints that dominate the organization of landscapes are investigated by a conceptual bucket approach. The temporal water balance dynamics are modelled, with vegetation water use efficiency being parameterized through the use of empirically obtained crop coefficients as surrogates of vegetation behavior in various developmental stages. Sensitivity analyses with respect to the root zone depth and soil water holding capacity are carried out with the aim of explaining the existence of preferential soil-vegetation associations and, hence, the spatial distribution of vegetation types within the study region. Based on these sensitivity analyses the degrees of suitability and adaptability of each vegetation type to parts of the study region are explored with respect of the soil water holding capacity, and the model results were found consistent with the observed affinity patterns.
\end{abstract}

\section{Introduction}

A primary motivation for this study is the development and implementation of a simple water balance model for regional applications in semi-arid Mediterranean landscapes, suitable to investigate the impact of climate change on regional wa-

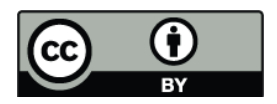

Correspondence to: V. Iacobellis (v.iacobellis@poliba.it) ter budget, and the assessment of critical climatic and landscape controls over large spatial domains (Entekhabi and Eagleson, 1989; Scholes and Walker, 1993), in absence of extensive soil database. According to Farmer et al. (2003) in such environments, often referred to as water-limited ecosystems (Rodriguez-Iturbe et al., 1999), the basic processes of water storage, drainage and evapo-transpiration are controlled by the interaction between climate (seasonality versus inter-annual variability), soil properties (storage capacity and drainage rates), and vegetation dynamics (soil moisture dynamics, plant productivity and security). Despite the prevailing spatial heterogeneity of climate and landscape properties (i.e., soils) and the highly complex space-time patterns of vegetation types, density and response, in order to estimate broad-scale elements of the water cycle (e.g. Milly, 1994), simplifications are necessary in model applications (e.g. Yates, 1997; Arnell, 1999: Oki et al., 2001; Doll et al., 2003). In fact, notwithstanding the process complexity, it has been found that even models with a single-layered root zone (e.g. bucket models) are quite often adequate to simulate monthly evaporation and water balance, at regional to global scales (e.g. Feddes et al., 2001; Federer et al., 2003).

In this field, several experimental studies have shown that water balance estimates are sensitive to land cover types, vegetation cover, and land use, as well as the rooting depth $D_{r}$, and available specific water content $\theta_{f c}-\theta_{w p}$ (e.g. Finch, 1998); therefore, the (quite commonly experienced) absence of accurate soil databases especially concerning the soil water storage capacity, represents a crucial limitation to the reliability of model predictions. Moreover, the existing methods to estimate the spatial maps of soil moisture storage properties (e.g. Santini et al., 1999) from multiple regression analyses with vegetation characteristics and land-use, on their turn are based on suitable geo-databases for testing the robustness

Published by Copernicus Publications on behalf of the European Geosciences Union. 
of these hypothetical regressions over the study domains.

On the other hand, in the latest decade the development of remote sensing has provided extensive and reliable maps of vegetation cover which are always available even in so-called ungauged basins. At the same time in the emerging field of eco-hydrology the role of vegetation in hydrology has been investigated in considerable detail.

Motivated by these considerations we explore the use of simple models for water balance evaluation and prediction, provided that they are able to correctly represent the role of climate-soil-vegetation (CSV) interactions and the dynamic adaptive behavior of vegetation in controlling the space-time patterns of water balance variability (Scanlon and Albertson, 2003). The analysis and detection of CSV interactions, in fact, may provide a priori information which can be exploited, in simple water balance models, to reduce parameter uncertainties that arise in absence of accurate soil databases, with the necessity to limit the use of model calibration procedures (Fiorentino et al., 2006).

It is well known, for instance, that during the evolution of native plant species in any environment, a diversity of mechanisms is adopted by plant communities to adapt their progeny to the range of environmental perturbations encountered in nature (Zobel, 1992). There is evidence that plants with different rooting habitats show different seasonal courses of water exploitation, and that the duration of water stress and the distribution of soil moisture with depth will determine whether a species can succeed in a particular environment (e.g. Davis and Mooney, 1986). The depth at which plants are able to grow roots has therefore important implications for the whole ecosystem hydrological balance (as well as carbon and nutrient balances). For example, the water extracted by plants during the wet season often comes from shallow layers where the root density is highest, whereas, as those layers dry, there is a progressive shift towards using water located in deeper layers (Canadell et al., 1996). In this regard, simulations with a simple water balance model across the large area of the United States (Milly, 1994) demonstrated that (estimated) actual values of soil water holding capacity were such that they were large enough to maximize evapotranspiration and minimize runoff, pointing to an ecologically optimal vegetation response relative to the magnitudes of water and energy supply.

In the same vein, we investigate if (and to what extent) the principles of eco-hydrology may play an important role even in heavily human impacted environments such as the EuroMediterranean region. In particular, the habitats for plant domestication, selected along the years by farmers on the basis of yield performance (Zobel, 1992), should provide reduced competition, improved fertility, and reduced disease incidence, thus allowing increased productivity. In such a case, vegetation response, and its evolutionary adaptation to the multi-scale climate variability and landscape properties (soils, topography etc.) prevalent in the study region, could be considered as keys to understanding the underlying wa- ter balance regimes, with particular reference to agricultural landscapes.

Therefore, since soil moisture storage capacity becomes a controlling factor for sustainability and survival of rainfed agriculture, some selective association between both soil and vegetation features should be recognized in their spatial co-variations, so that the key problem of identifiability of model parameters could be effectively constrained. Thus, land cover information, available at a regional scale, could be further exploited in order to improve the hydrologic evaluation and prediction of water balance and reduce the parametric uncertainty due to scarce information about soil features and hydraulic behavior.

We use a conceptual bucket model. The water balance behavior of each land cover (vegetation) type is explored through sensitivity analysis with respect to soil water storage capacity, and through assessing the effects of climate variability (at intra- and inter-annual time scales) under different soil and vegetation conditions. The adaptation and suitability of each vegetation type to local conditions (and in the absence of irrigation) are then investigated in terms of (estimated) annual rate of evapo-transpiration being this a proxy of plant productivity. Finally, a conceptual validation of this rationale is performed by observing how the evapo-transpiration response simulated by the model under different vegetation and soil combinations reflects the apparent spatial patterns of vegetation types across the study region.

The paper outline presents a background description of the study region with its climatic and landscape peculiarities and analyzes the soil and vegetation patterns observed in the study region by the light of the available soil database. Then, the water balance model is briefly described as well as the soil and vegetation data used in the model simulations. The results section is focused on the water balance response under different soil and vegetation conditions, followed by the sensitivity analysis carried out to investigate vegetation adaptability.

\section{Background to the study region}

Puglia, South-Eastern coastal region of Italy (Fig. 1), exemplifies typical features of semi-arid Mediterranean landscapes. Over many centuries, mild orographic features and high population density have led to intensification of agricultural farming, accompanied by replacement of existing natural vegetation with agricultural crops (Table 1). Some of these crops have originated from native species as in the case of olives, grapes and some varieties of wheat. Exotic species (e.g., some types of vegetables) have also been introduced over time. This is exemplified by a low degree of crop diversity in the region covering an agricultural area of about $14700 \mathrm{~km}^{2}$, of which $43 \%$ is cultivated with wheat, 


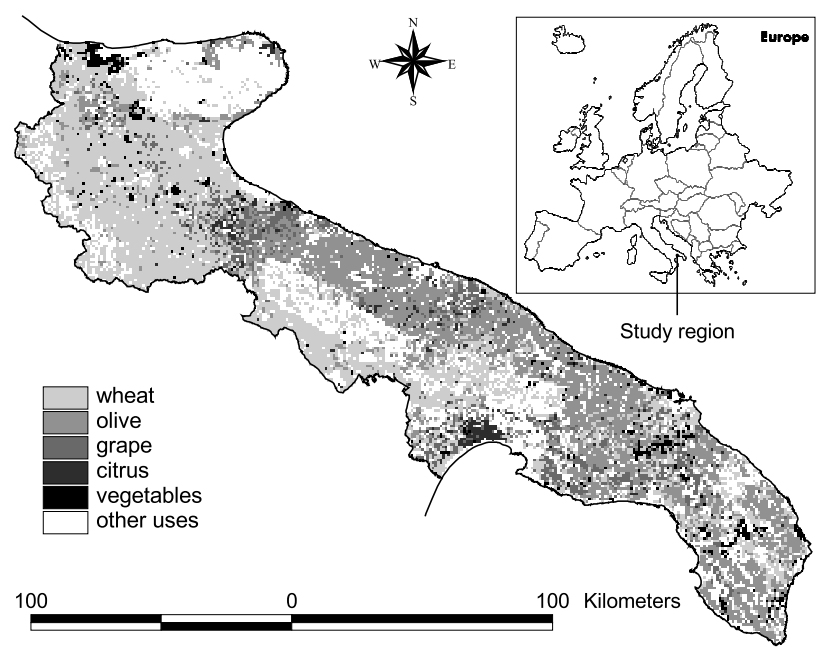

Fig. 1. Map of study area with spatial distribution of crops under consideration. The notation "other uses" refers to natural areas, other agricultural uses and urban areas.

Table 1. Land-use summaries of Puglia region (Southern Italy)

\begin{tabular}{lccc}
\hline & $\begin{array}{c}\text { Area } \\
\mathrm{km}^{2}\end{array}$ & $\begin{array}{c}\text { Area } \\
\%\end{array}$ & $\begin{array}{c}\text { Area, \% of } \\
\text { antecedent figure }\end{array}$ \\
\hline Study site & 19332 & 100 & - \\
Human-modified & 15776 & 81.6 & - \\
Natural & 3556 & 18.4 & - \\
Vegetation cover & 18243 & 94.4 & - \\
Agricultural use & 14687 & 76.0 & 80.5 \\
Simulated species & 12779 & 66.1 & 87.0 \\
Irrigated crops & 2175 & 11.3 & 17.0 \\
\hline
\end{tabular}

$32 \%$ with olives, $9 \%$ with grapes, $3 \%$ with citrus and $2 \%$ with vegetables (Fig. 1).

A major distinction can be made between permanent and seasonal crops. In fact, a marked differentiation exists between seasonal (e.g. winter wheat) and permanent native vegetation (e.g. olives) in terms of their physiological features (e.g. root apparatus) to deal with variable soil moisture storage (Zobel, 1992). Seasonal crops, represented here by wheat crops, are usually characterized by an almost complete vegetation ground cover with a high root density and shallow root depth. These features make seasonal vegetation able to maximize soil water exploitation only during and immediately after the wet season (Canadell, 1996). On the other hand, permanent tree crops, represented by olives, grapes, and citrus, have lower percentages of vegetation ground cover, deeper roots and lower root density, which have all evolved over time to withstand the expected soil moisture deficits during the dry season.
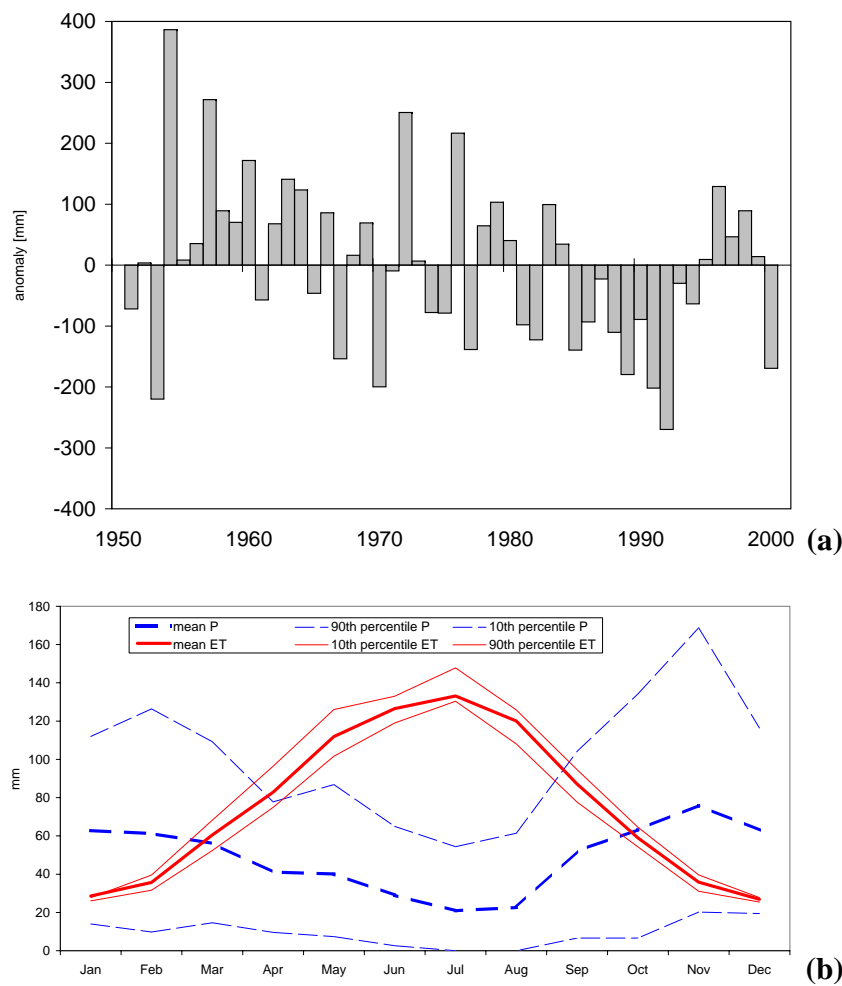

(b)

Fig. 2. Inter-annual (top) and intra-annual (bottom) variability of climate: (a) fluctuations of annual rainfall totals above and below mean annual rainfall; (b) mean monthly values (tick lines) of rainfall and the potential evapo-transpiration and their inter-annual variability range expressed as 10th and 90th percentiles. The average annual rainfall is $588 \mathrm{~mm}$, while the average annual reference evapo-transpiration is $1136 \mathrm{~mm}$.

Besides physiological features of plants, the spacing of trees, which in turn controls vegetation ground cover, is determined by local agricultural practices aimed at maximizing productivity and reducing disease exposure. Typical ground cover conditions observed in the region as well as details on harvesting and pruning time are presented in Table 2 (Allen et al., 1998) for seasonal and permanent crops respectively.

The climate variables in this region typically exhibit marked inter-annual variability (especially in rainfall, Fig. 2a), as well as intra-annual seasonality (Fig. 2b) where the observed seasonal rainfall pattern is out of phase with that of potential evapo-transpiration.

A soil geo-database is available for the study region (Caliandro et al., 2005), which consists of more than 5000 observations that were collected between 1997 and 2000 to develop a new soil map for agricultural land planning and management. The survey uniformly covered the agricultural portion of the region (covering about $14700 \mathrm{~km}^{2}$ ). Most of these observations (about 4000) were based on soil cores dug to a maximum depth of $1.50 \mathrm{~m}$ and analyzed on site by trained experts adopting simplified qualitative methodologies. 
Table 2. Water use efficiency parameters, modified from Allen et al. (1998) after lsymeter experimentations at the local scale (Caliandro et al., 2005); local adjustment of the crop coefficients take into account the peculiarity of climate and the typical cultivars and agricultural practices. Figures reported in bold character indicate harvesting time for the seasonal crop (wheat) and pruning time for permanent ones, while figures in italic character refer to the dormancy period in which bare-soil evaporation is the dominant atmospheric loss from the soil water.

\begin{tabular}{lcccccccccccc}
\hline Crop $K_{c}$ & Jan & Feb & Mar & Apr & May & Jun & Jul & Aug & Sep & Oct & Nov & Dec \\
\hline Wheat & 1.00 & 1.00 & 1.10 & 1.12 & 0.65 & $\mathbf{0 . 3 0}$ & 0.30 & 0.30 & 0.30 & 0.30 & 1.00 & 1.00 \\
Olives $^{\mathrm{a}}$ & $\mathbf{0 . 5 0}$ & 0.50 & 0.50 & 0.50 & 0.50 & 0.50 & 0.50 & 0.50 & 0.50 & 0.50 & 0.50 & 0.50 \\
Grapes $^{\mathrm{b}}$ & $\mathbf{0 . 4 0}$ & 0.40 & 0.40 & 0.50 & 0.60 & 0.75 & 0.75 & 0.60 & 0.40 & 0.40 & 0.40 & 0.40 \\
Citrus $^{\mathrm{c}}$ & 0.75 & 0.75 & 0.70 & 0.70 & 0.70 & $\mathbf{0 . 6 5}$ & 0.65 & 0.65 & 0.65 & 0.65 & 0.70 & 0.70 \\
\hline
\end{tabular}

${ }^{a}$ Values with ground cover equal to $50 \%$; $^{\mathrm{b}}$ Values with ground cover equal to $35 \%$; ${ }^{\mathrm{c}}$ Values with ground cover equal to $70 \%$.
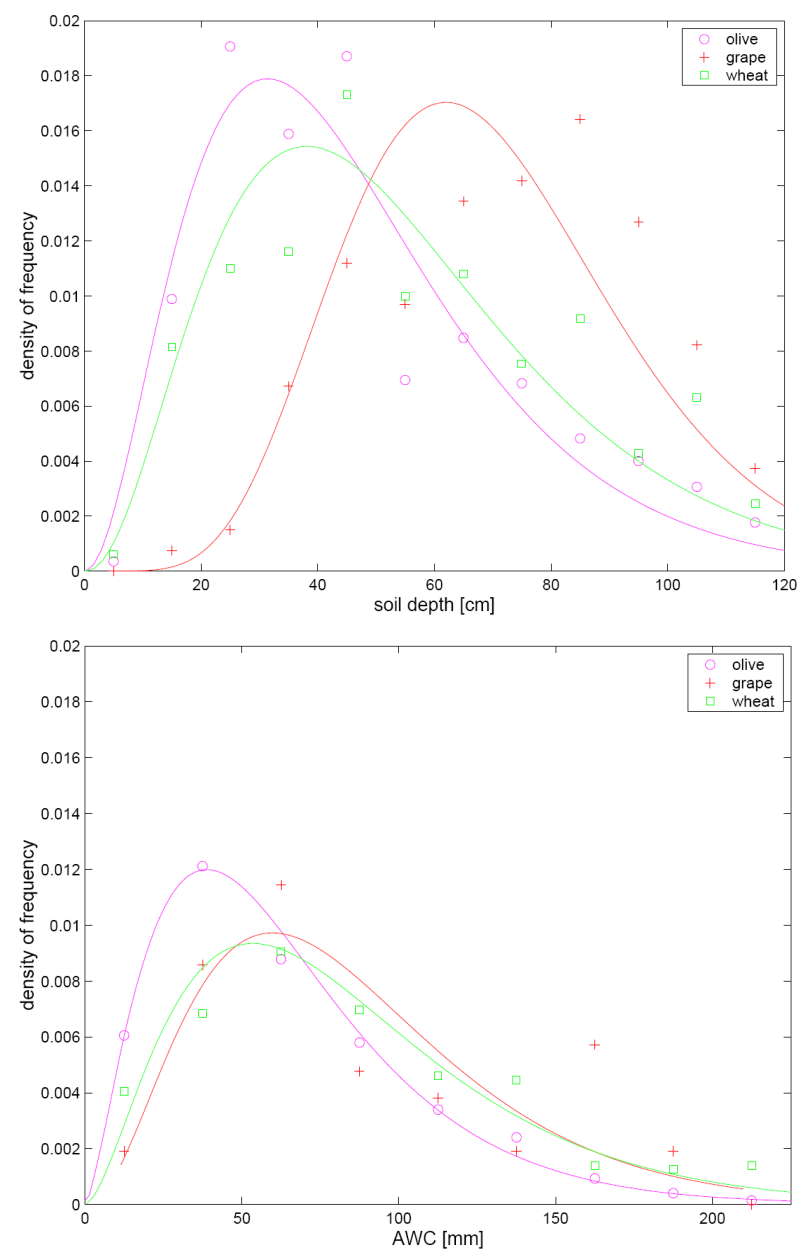

(a)

Fig. 3. Empirical and fitted probability density functions (a measure of abundance) of soil environmental variables; (a) with regard to soil depth sub-samples for olive (mean $=46.0 \mathrm{~cm}$; st.dev. $=25.5 \mathrm{~cm})$, wheat $($ mean $=54.4 \mathrm{~cm} ;$ st.dev. $=27.4 \mathrm{~cm})$, and vineyards $($ mean $=70.6 \mathrm{~cm}$; st.dev. $=22.7 \mathrm{~cm})$; (b) with regard to AWC sub-samples for olive $($ mean $=64.4 \mathrm{~mm}$; st.dev. $=40.6 \mathrm{~mm}$ ), wheat $\quad($ mean $=84.5 \mathrm{~mm}$; st.dev. $=48.8 \mathrm{~mm})$, and vineyards (mean $=85.9 \mathrm{~mm}$; st.dev. $=48.1 \mathrm{~mm}$ ).
Total soil depth and available water capacity (AWC) were recorded among other features such as soil texture and structure, terrain elevation, slope and aspect, landuse, vegetation, litology, groundwater level, drainage condition, and permeability. The AWC (mm) is estimated by accounting for all soil layers available within the root zone.

\subsection{Detection of soil-vegetation affinity and preferential as- sociation}

When ecologists investigate variation of plant or animal communities across a range of different environmental conditions, usually not only large differences in species composition of the studied communities are found, but also a certain consistency or predictability of this variation (e.g. Lepš and Šmilauer, 2003).

Accordingly, we investigate on the available geo-database of soil samples introduced in background section (Caliandro et al., 2005) that provided a valuable source of information on soil depth and soil water holding properties for the study region.

In the available soil database, the individual samples have information only on one single vegetation species observed in site. Therefore we can analyse the vegetation species composition in terms of various abundance measures, including counts and frequency estimates, only if we refer to the available data set as a multiple-sites sample.

In practical terms, the response variables representing the community composition is given by the presence of a given vegetation species, while the explanatory data set contains measurements of the environmental properties, namely soil depth $(\mathrm{cm})$ and AWC $(\mathrm{mm})$. In turn, the quantitative and presence-absence variables representing the species composition may also occur as explanatory variables to predict expectable conditions for some environmental variable of interest.

In Fig. 3, for the three dominant land-uses (Table 4) frequency distributions are shown as abundance measures with respect to the adopted environmental variables. By fitting a gamma probability distribution function to the soil variables, as in Milly (1994), it is possible to explore the response level 
Table 3. Central values and expected variability bounds of model parameters.

\begin{tabular}{lcccc}
\hline Parameter & Wheat & Olive & Grape & Citrus \\
\hline Root Depth $(\mathrm{cm})$ & $80 \div 100$ & $70 \div 130$ & $90 \div 130$ & $100 \div 120$ \\
$b_{c}=\theta_{f c}-\theta_{w p}(\%$ vol. $)$ & $6.4 \div 19.5$ & $6.4 \div 19.5$ & $6.4 \div 19.5$ & $6.4 \div 19.5$ \\
\hline
\end{tabular}

field capacity $=\theta_{f c} ;$ wilting point $=\theta_{w p}$

Table 4. Composition of land-use types and numbers of soil samples classified by their land-use attributes.

\begin{tabular}{lcccc}
\hline & Area $\left[\mathrm{km}^{2}\right]$ & Area [\%] & Soil Samples & Soil Samples [\%] \\
\hline Total & 19332 & 100 & 3967 & 100 \\
Wheat & 6850 & 35.5 & 1202 & 30.3 \\
Olive & 4828 & 25.0 & 1575 & 39.7 \\
Vineyards & 1266 & 6.6 & 246 & 6.2 \\
Other land-uses & 6388 & 33.0 & 940 & 23.7 \\
\hline
\end{tabular}

of a species with respect to an environmental gradient variable (Gauch and Whittaker, 1972); therefore, theoretically the value of environmental variable that gives the maximum abundance represent the optimum value, while the amplitude of response (like measures of dispersion) is a measure of environmental tolerance. From such an analysis (Fig. 3a and b), it is clear that the abundance of the three considered species is basically correspondent to specific ranges of soil depth and AWC conditions.

In particular, the range of values for the soil AWC observed in the real data (Fig. 3b) is coherent with those values estimated on the basis of literature ranges of root depths and soil textural properties (Table 3). Nevertheless, differences are revealed between their shapes. Olive plants seem well suited even to small values of the AWC parameter, while wheat and grape appear less tolerant. These features shown by the frequency distributions of water holding capacity well represent the selectivity (grapes and wheat) and conversely the adaptability (olives) of main vegetation types to various landscape conditions in the region.

Furthermore, the dependence between spatial occurrence of land-use types and soil attributes across the landscapes is clarified in terms of patterns of relative abundance of the considered land-uses in any given class of soil water holding capacity. Based on the soil samples, Fig. 4 presents the relative frequencies of each land-use varying the AWC. The use of frequencies normalised by the relative abundance of each soil class within the entire sample assures more significant and unbiased signals of soil-vegetation affinity. The observed patterns show that increasing the available water content of the soil implies a regular transition (or substitution) from less water-consuming crops (more adaptable) to more exigent ones (more selective).

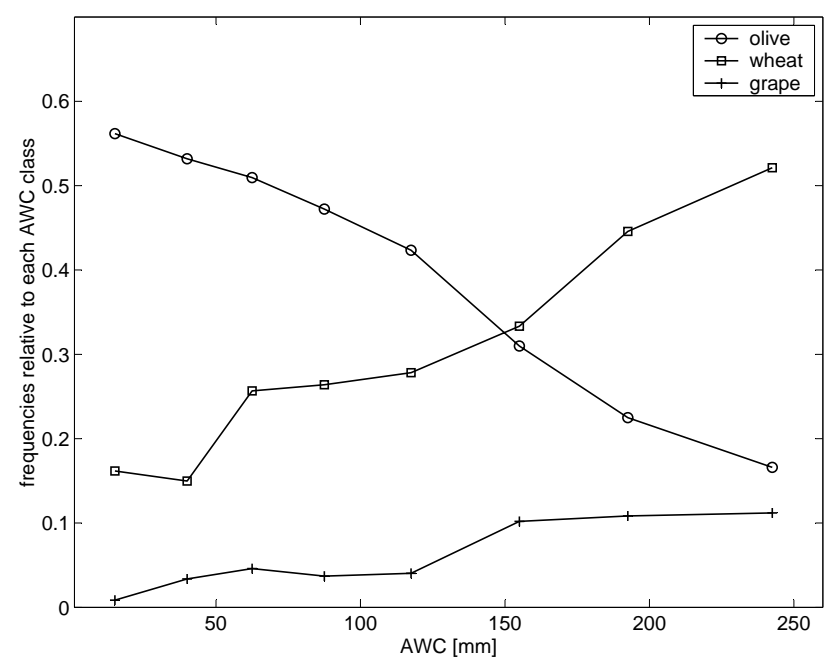

Fig. 4. Relative frequencies of soil samples conditional on soil use with respect to AWC classes.

Therefore, the shapes of these curves (and their slopes) provide an explanation of the affinity trends between landuse and water holding capacity. In fact, according to Fig. 4, wheat crops tend to dominate above $150 \mathrm{~mm}$ of AWC with noticeable improvements as this threshold is exceeded. Similarly grape crops reach a stable condition for AWC values above $150 \mathrm{~mm}$. On the other hand, olive groves that are adaptable to a wider range of landscape conditions in the study region appear gradually substituted by other more profitable crops. As for the natural biomes, this gradual change in the community composition can be related to differing, but partially overlapping demands of individual species for environmental factors such as the available soil moisture, AWC. 
Based on these results, we can make conclusions about the preferences of individual plant species' populations for particular environmental gradients, which are described by the measured soil properties.

On the other hand, though the establishment of crop species is based on a yield maximization principle that encompasses other criteria like terrain slope, and feasibility of plantations, the substitution of less remunerative cultures such as the olives with more rewarding ones, such as wheat, seems to prevail in the land-use composition. The observed co-occurrence of land-use and soil properties provides evidence that eco-hydrological principles play a crucial role even in human-modified landscapes that are strongly characterized by agricultural vegetation in a water limited environment, thus providing a useful guidance for model parameterization and constraint.

\section{Description of the water balance model}

This paper section mainly focuses on the role of soil and vegetation in regulating the landscape water balance. Therefore, model simulations are utilized to explain and explore differences in the soil moisture response due to different vegetation types. In particular, the temporal variability of water balance resulting from simulations is used to interpret the spatial patterns of soil-vegetation occurrences extracted from the statistical analysis of available soil data over the study region.

For the specific orographic and geological setting of the study region, we focus on vertical fluxes of evapotranspiration to the atmosphere, and evaluate drainage from the root zone, including any surface or subsurface flow. Hence, modeling a single-layer root zone is deemed adequate to simulate monthly water fluxes, though ignoring several processes of water movement which become more important at the daily time scale (Federer et al., 2003). Such an assumption is corroborated from the fact that the aquifer level lays far below the root zone almost everywhere in the study region.

In the single-layer root zone, soil moisture state variable $S(t)$ is updated on the basis of known or estimated net inflows and outflows to and from an associated control volume. The resulting dynamic water balance equation is given by:

$S(t+1)=S(t)+P-E_{T}-Y$

where, $P$ is the rate of precipitation, $E_{T}$ is the rate of actual evapo-transpiration, $Y$ is the net drainage yield (i.e. the rate at which water is leaving the root zone), and $t$ is the generic time step. The magnitudes of fluxes on the right-end-side of Eq. (1), namely, $E_{T}$, and $Y$, are all controlled by the soil water storage $S(t)$. To estimate these fluxes in terms of $S(t)$ (with the assumed mathematical expressions being summarized in Appendix A) the soil moisture capacity, $S_{b c}(\mathrm{~mm})$, is the limiting factor (e.g. Milly, 1994; Struthers et al., 2003;
Federer et al., 2003). This model parameter $S_{b c}$, representing the soil storage capacity per unit area, is assimilated to the AWC and is given by the product of the soil depth available for plant roots $D_{r}(\mathrm{~cm})$ and the difference between the soil moisture at field capacity $\theta_{f c}(\%)$ and at wilting point $\theta_{w p}(\%)$.

Such a model structure is specifically adopted in order to control soil moisture behavior and concentrate its variability into one single parameter. The sensitivity of model predictions to the parameter $S_{b c}$ will be reported later on.

Monthly evapo-transpiration is modelled on the basis of the Penman-Monteith equation, after the FAO calculation method (Allen et al., 1998). The influence on evapotranspiration exercised by canopy architecture, leaf cover density, and root apparatus is embedded into empirical crop coefficients $K_{c}$ describing vegetation development stages with respect to some standard vegetation type. Similarly, the influence of soil water deficit on the stomatal resistance considered in the Penman-Monteith formulation is taken into account through an empirical water stress conceptualization on the basis of the available water in the root zone, again as suggested by the FAO method known as non-standard evapotranspiration (Allen et al., 1998) (see Appendix A).

Both for seasonal and permanent crops $K_{c}$ values are variable during the year reflecting the seasonal developmental stages of plants under particular climatic conditions. A database of crop coefficients for typical Mediterranean crops was provided by Doorenbos and Pruitt (1977), and later supplemented by Allen et al. (1998) (Table 2). In Table 2, as suggested by the FAO method (Allen et al., 1998), the crop coefficients were modified with respect to the literature values on the basis of lisymeter studies developed in the study region to account for the peculiarity of climate that reflects on plant development and therefore soil water exploitation (Caliandro et al., 2005). The most evident adjustment in the crop coefficients is that of the winter wheat with its anticipated development and maturation in the early spring.

Four typical crops are considered in model simulations, namely wheat, olives, grapes, and citrus, because they represent most of the agricultural areas within the Mediterranean region.

As for the crop coefficients, the allowable limits of root depth for each species are taken from Allen et al. (1998) and revised through local observations (Caliandro et al., 2005). The estimates of $D_{r}$ are expressed in terms of ranges of variability (up to $\pm 30 \%$ ) observed in the region (Table 3 ). Similarly, $\theta_{f c}$ and $\theta_{w p}$ are highly variable between the different soil types that exist in the study region. The possible range of values defining soil water holding capacity is reported in Table 3 as obtained from the regional soil database. Consequently, the variability of the soil storage capacities can cover a range of about $\pm 70 \%$ if any dependence between root depth and soil properties is neglected.

The water balance simulations are initially carried out for central values of the variability range that characterizes the 
soil water storage capacity, $S_{b c}$, as estimated from central values of $D_{r}, \theta_{w p}$ and $\theta_{f c}$ in their respective variability ranges. With this parameter set, the model was run for a 50-year data set (1951-2000) of monthly climate records in order to capture specific water balance responses to the intraannual and inter-annual climate variabilities that can be related to landscape attributes in the study region. The climate records are taken from a meteorological station that is centrally located and is considered climatically representative of most of this territory. Each vegetation species is assumed to be under stationary conditions, repeating their annual development cycle as represented by the crop coefficients reported in Table 2 in which harvesting and pruning times are also indicated. In the case of permanent tree crops, we refer to mature plants.

Subsequently, the simulations were repeated covering the full range of possible values for the bucket capacity $S_{b c}$ and recording estimates of the water balance fluxes (evapotranspiration and drainage) and the soil moisture storage. A comparison between model simulations resulting from daily and monthly formulations is presented in Appendix B to demonstrate the limited bias of the monthly water flux predictions for the reported study case.

\subsection{Climate-soil-vegetation impacts on water balance}

The selection of results presented below is aimed at recognizing and conveying differences among the various vegetation species in terms of hydrologic response and climate adaptation which can be useful to explain the observed spatial occurrence of vegetation and soil features. The vegetation response to intra-annual and inter-annual variability of climate is presented in the form of associated behavior patterns, or signature plots (Atkinson et al., 2002; Farmer et al., 2003).

The central values of root depths and soil water capacity (used for the initial simulations) in their respective variability ranges (Table 3 ) are not significantly different between the various crops: it is either $100 \mathrm{~cm}$ (olives, wheat) or $110 \mathrm{~cm}$ (grapes, citrus), and the remaining soil properties are in fact identical. Hence, the differences in the average drainage yields between different crops, and the differences in drainage yields between different years that may yet have similar rainfall totals, are consequence of the differences in plant water use (i.e., crop coefficients and moisture dynamics). In particular, the seasonal cycle of rainfall and potential evapo-transpiration determines strong intra-annual variability of soil moisture and consequently drainage yield.

Always using central values of root zone depth and soil properties, the model estimated the mean monthly drainage yields, which are presented in Fig. 5a (continuous lines). Model simulations highlighted significant differences between the crops, with grapes having the greatest water yield on average, followed by olives. Wheat and citrus, although representing very different vegetation types, exhibit almost identical hydrological responses, but with lower an-
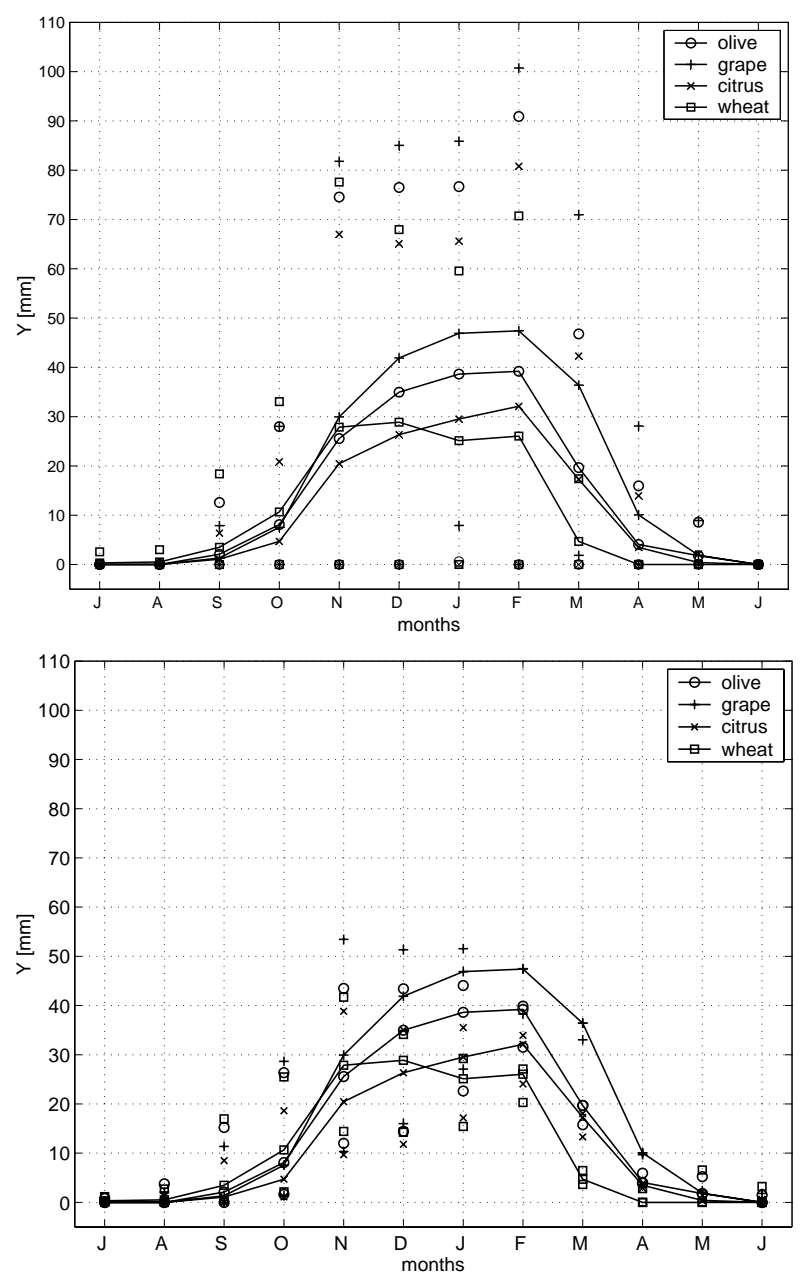

(a)

Fig. 5. Drainage response of the four vegetation types at the intraannual scale. (a) variability due to climate fluctuations; continuous lines represent mean monthly drainage yields based on 50-year of simulations, while magnitude of inter-annual variability for each month is marked with dots shifted from the mean curves by as much as one times the standard deviation of the monthly simulation results. (b) Sensitivity of the mean monthly drainage yield (based on 50-years simulations) to soil moisture storage capacity, $S_{b c}$, where continuous lines refer to median soil storage conditions and dots correspond to the use of minimum and maximum values of $S_{b c}$ found within the region.

nual yields than grapes and olives. Moreover, these mean curves reflect the seasonal patterns of climate (rainfall and potential evapo-transpiration) and the seasonal cycle of plant water use (as reflected in the crop coefficients). Wheat crops, for example, exhibits the lowest average water yield during winter months since they correspond to its growth period, whereas for permanent crops (e.g., olives, grapes) the highest water yields are obtained from the concurrence of high winter rainfall and relative plant dormancy. 
Figure 5a also presents measures of the inter-annual variability of monthly drainage yield, in the form of excursions above and below the mean curve. One can see that the interannual variability is particularly high during winter months for all of the vegetation species, clearly reflecting the interannual variability of rainfall in the wet season. In the early autumn period, however, the wheat crop shows the greatest variability, since this period corresponds to pre-seedling and early development of that crop when its evapo-transpirative demand is reduced, as seen in Table 2. The effects of rainfall deficit conditions are also evident in Fig. 5a, with deep drainage falling quickly to negligible values in dry years for all (including winter) months.

The simulations also reproduced significant inter-annual variability of drainage, ranging from less than $50 \mathrm{~mm} /$ year to about $600 \mathrm{~mm} /$ year for the various crops. Evidently, much of this variability can be attributed to the corresponding large inter-annual variability of annual rainfall (ranging from less than 400 to about $950 \mathrm{~mm} /$ year). Nevertheless a significant inter-annual variability of drainage yield, of the order of 100 to $150 \mathrm{~mm} / \mathrm{year}$, is exhibited also between years with similar annual rainfall totals. This component of the total interannual variability can be explained by the intra-annual (deterministic and random) variability of rainfall, interacting with intra-annual variability of potential evapo-transpiration, to produce variable soil moisture dynamics and drainage yield within and between years.

On the other hand, by varying the soil depth and soil moisture storage parameters, the sensitivity of monthly water yield to different soil settings was analysed. Figure $5 \mathrm{~b}$ presents the mean monthly values of the simulation results, where the solid lines represent the mean monthly yields for central values of $S_{b c}$ (same as Fig. 5a). In addition to these, the results corresponding to the maximum and minimum values of $S_{b c}$ in the ranges defined Table 3, are presented as points, to remark the ranges of variability in the mean monthly yields that can be expected due to soil storage properties. The results presented in Fig. $5 \mathrm{~b}$ indicate that the greatest variability in drainage yield is achieved in the late autumn period (November), as this corresponds to the period of moisture recovery after the summer deficit, when the superposition of variability of $S_{b c}$ and intra-annual rainfall variability combines together to cause this effect. It is clearly evident therefore that the effect of changes in $S_{b c}$ on drainage yield progressively reduces in the winter, and from late winter till late summer it is almost negligible. In late winter field capacity conditions are reached on average for all realistic values of, $S_{b c}$ and hence the water yield does not depend on it. In summer, on the other hand, soil moisture status is considerably low regardless of the soil storage capacity, and therefore drainage yield is, once again, not in any way impacted by the assumed maximum value of $S_{b c}$.

A comparison of the results presented Fig. 5a and Fig. 5b also indicate that in such an environment the variability of the hydrological responses due to variability of $S_{b c}$ values is significant but considerably smaller than that due to the inter-annual fluctuations of climate, which were previously reported, especially during winter months. Consequently, it can be argued that in order to assure plant survival and security in the Mediterranean region, vegetation must develop more effective strategies to adapt to the large inter-annual variability of climate than those needed to be successfully adapted to other landscape features controlling soil moisture storage (i.e., through increases of root depth). In particular, they must focus on adjusting their plant water use to be more closely aligned with the temporal patterns of rainfall and the resulting patterns of soil moisture.

\subsection{Vegetation adaptive strategies and hydrological de- scriptors}

In this section we explore the adaptive strategies that may have been employed by the various vegetation species to survive and succeed in the semi-arid Mediterranean landscape. The basic hypothesis is that the vegetation species develop strategies to maximize their productivity within the limited resources available (energy, water, nutrients etc.), and, on the other hand, they withstand periodic shortages of these resources that arise due to the natural variability of climate (Zobel, 1992). In other words, species that are naturally adapted to the local conditions are those that concurrently maximize mean productivity and minimize the variance of the productivity. With respect to the water uptake, the strategies they have under their disposal are 1) maximize the reach of the root apparatus to access more of the annual rainfall, and 2) maximize security against water stress by adopting a seasonal plant water use pattern that is aligned with the climate (water and energy). In model simulations, both strategies are accounted for by varying the root zone depth and soil moisture storage parameters within the expected range of soil properties that are present in the study region and by comparing the evapo-transpiration performance of different crops (essentially represented by the seasonal patterns of the specific crop coefficients $K_{c}$ in Table 2). In fact, the mean monthly potential evapo-transpiration turns out to be larger than mean monthly rainfall for a significant period of the year for all of the investigated crops (though with considerable differences between crop types), with wheat having its period of maximum evapo-transpiration from late winter till mid-spring (February to May), while tree crops (particularly grapes and olives) maximize their water exploitation from spring to summer (March to September). In other words, for all plants water stress conditions are likely to occur over considerable (though different) periods in the absence of irrigation. The impact of these adaptation strategies are investigated in terms of the mean and variance of actual evapotranspiration, these being used as surrogate measures of plant productivity and security against water stress, respectively.

The results of the sensitivity analysis to soil moisture storage capacity, $S_{b c}$, are first presented in terms of mean and 


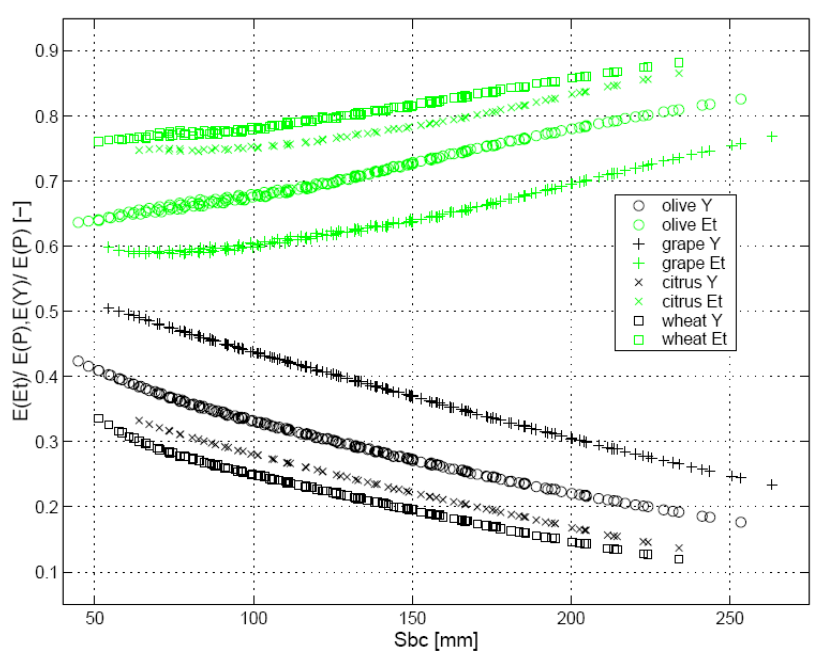

Fig. 6. Sensitivity of the mean annual evapo-transpiration $E\left(E_{T}\right)$ and drainage yield $E(Y)$ to changes in soil moisture storage capacity, $S_{b c}$. The various curves refer to mean annual values scaled by the mean annual rainfall, $E[P]$, based on 50-year water balance simulations.

inter-annual variability of water fluxes. Figure 6 shows the sensitivity of mean annual evapo-transpiration and drainage yield to the range of soil storage parameters defined in Table 3. As expected, the increase of $S_{b c}$ produces a beneficial increase in actual evapo-transpiration, and a corresponding decrease of drainage yield, by assisting plants to capture a larger fraction of the annual rainfall. This sensitivity of the hydrological response to $S_{b c}$ may also be taken as an indication of the heterogeneity of actual evapo-transpiration and drainage yield estimates across the region, arising from the heterogeneity of soil storage properties (root depth, field capacity and wilting point).

This hypothesis to recognise naturally adapted vegetation is further investigated by exploring the effectiveness of increasing $S_{b c}$ for stabilizing plant productivity, and in particular, for reducing the inter-annual variability of actual evapotranspiration. Figure 7 presents the coefficients of variation of the annual actual evapo-transpiration $\left(C V_{E t}\right)$, which is used as a measure of the inter-annual variability of plant productivity. Results indicate, in general, that increases of $S_{b c}$, besides clear improvements in the mean annual evapotranspiration (Fig. 6), also produce substantial decreases in the inter-annual variability once some threshold of $S_{b c}$ is exceeded. This is due to more of the water being carried over to subsequent months and being available for plant water use, and not lost through deep drainage. Native permanent species, i.e., olives and grapes, show the greatest sensitivity to soil moisture storage capacity, and reach the same degree of residual variability, which suggests the effective use of soil moisture storage capacity as an adaptation strategy to deal with climate variability. For winter seasonal crops (e.g.,

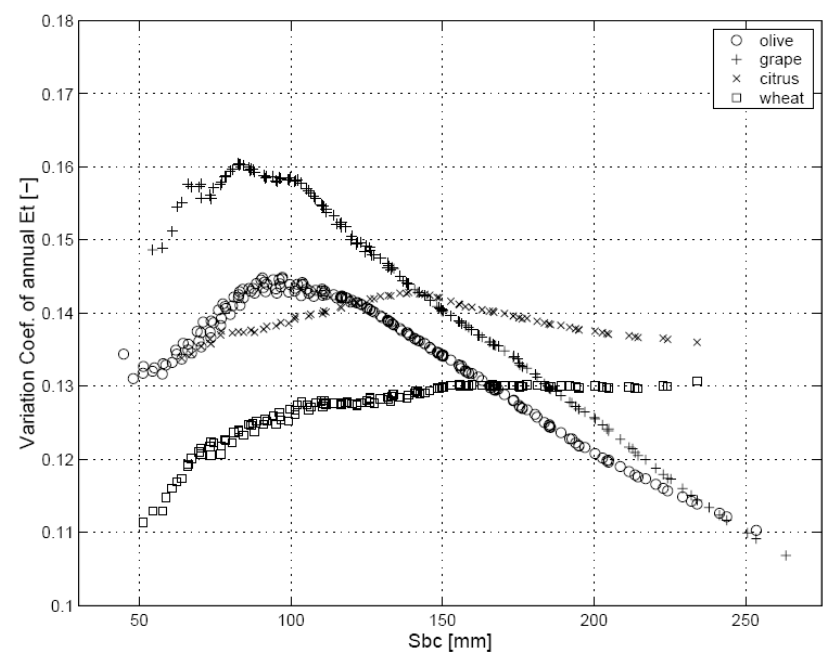

Fig. 7. Influence of soil moisture storage capacity $S_{b c}$ on the coefficient of variation of the estimates of annual actual evapotranspiration.

wheat) the sensitivity to soil moisture storage capacity is not as strong as olives and grapes, because their growth period coincides with the period of low rainfall variability, helping to ensure that they are less dependent upon the carryover of soil moisture storage. In fact, the coefficient of variation for wheat presents an almost constant value for $S_{b c}$ values greater than $150 \mathrm{~mm}$, indicating a substantial non-sensitivity of the inter-annual variability to any increase of storage capacity. On the other hand, citrus appears less sensitive to the soil moisture storage capacity, with the highest residual variability among the studied crops, indicating that citrus crop is not as well suited to the local climate without irrigation.

The analysis of $C V_{E t}$ can be used to estimate expected values of $S_{b c}$ needed to optimize plant performance in terms of both productivity and conservation. In all four cases, in fact, the rising limb of the $C V_{E t}$ curve represents unfavorable conditions of stable but low evapo-transpiration from year to year that determine the occurrence of frequent water stress conditions as a consequence of limited moisture storage within the soil. Consequently, specific suitability ranges for $S_{b c}$ can be recognized for the modelled vegetation types (Fig. 7), thus providing an explanation for the observed spatial patterns of vegetation and soil properties highlighting variable degrees of affinity (Fig. 4). According to the performed sensitivity analysis, grape and olive crops seem to be adaptable to the climatic conditions in the study region for soil moisture capacities above $75-100 \mathrm{~mm}$, whereas wheat and citrus would have good performances for $S_{b c}$ values greater than 140-150 mm (Fig. 7).

Besides $C V_{E t}$ a second important hydrological descriptor is the mean annual value of the actual evapo-transpiration $E_{T}$ scaled by the annual potential crop evapo-transpiration $E_{T c}$ (Fig. 8). This ratio is a measure of the annual plant 


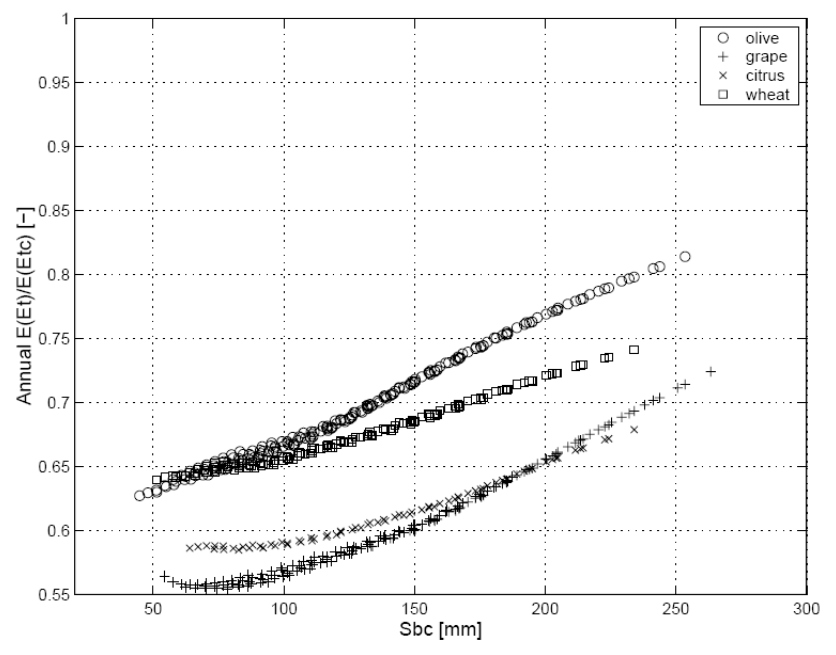

Fig. 8. Influence of soil moisture storage capacity $S_{b c}$ on the ratios between actual and potential annual evapo-transpiration for the experimented crops.

productivity, representing the variable degree of adaptation in response to the water storage capacity of the soil. In Fig. 8, wheat and olive crops show better performances among the considered species, whereas grapes and citrus are far below, thus appearing to be less adapted.

\section{Conclusions}

This research explores whether, the interaction in a challenging environment between human (or socio-economic) and natural processes, that led to the adoption of typical "naturally" selected crops, can be explained through the analysis of water balance dynamics. It pursues a dual goal. On one hand we need to assess the role of the eco-hydrological concepts of natural selection and productivity optimization to landscapes deeply affected by human intervention and dominated by agricultural vegetation species. On the other hand we examine the suitability of simple hydrological models for water balance evaluation and prediction under conditions of limited data availability (i.e. in ungauged basins).

The first issue is already accomplished in Sect. 2 where the existence of preferential patterns and selectivity associations is clearly detected in the study region thus supporting the conclusion that ecohydrological concepts of competition and selectivity also apply to agricultural crops.

Regarding the second one, a monthly bucket model is proven to be able to fairly reproduce the aforementioned ecohydrological processes, providing a simple scientific explanation of the observed patterns of vegetation cover and associations between vegetation and soil types and thus gaining robust, though non-conventional, validation of the modelbased hypotheses. The model also has the advantage of simple process parameterizations which assisted in containing the uncertainty of prediction. In fact, the above men- tioned eco-hydrological associations permitted the evaluation of probability distributions of soil hydraulic properties conditional on the vegetation cover (see Fig. 3). Such information, within a Bayesian context of model uncertainty evaluation can be highly informative when considering that soil properties are rarely available at regional scale while vegetation and land cover information is one of the products that can be most effectively obtained by remote sensing observation.

The water balance estimations, obtained through model simulations, were focused first on the temporal dynamics of water balance with regard to vegetation impacts in Mediterranean water-limited environments. In such conditions, much of the inter-annual variability is due to the interannual variability of rainfall. Nevertheless, there are significant differences between vegetation types in the way their phenology is adapted to the climate, as exemplified by the assumed crop coefficients. For example, where vegetation activity is in phase with rainfall the water yield is reduced as happens for wheat crops. On the contrary, if the wet season corresponds to the plant dormancy period, as for grape crops, the water yield is maximized.

In the second part of the results section, model sensitivity analysis is reported in order to explore the vegetation response to variable soil properties, namely soil type and depth available for plant roots. In particular, the impact of soil properties on the overall water balance is clarified. Depending on the different types of vegetation, increasing values of the soil moisture storage capacity, $S_{b c}$, leads to an increase of actual evapotranspiration and a decrease of the drainage yield, due to the increase in the carry-over of soil moisture from wet to subsequent dry periods. Consequently, the spatial variability of $S_{b c}$ can contribute significantly to the variability of hydrological responses at the annual scale, although it is most important during the autumn, wetting up period. Nevertheless, at least for the range of values of $S_{b c}$ used, the model simulations also showed that the variability of hydrological response caused by the soil parameters is much smaller than the variability caused by climate (rainfall) random fluctuations in this region.

Subsequently, the concepts of maximum plant productivity and security are employed to discuss the suitability and adaptation of these vegetation types to the semi-arid Mediterranean climate and landscapes. It is assumed that to survive in water-limited environments plants adapt their physiology in such a way as to exploit water during periods of abundance (e.g. seasonal winter crops), and secondly to adjust the soil moisture storage capacity at their reach by extending the root depth (e.g. olive and grape). According to the hydrological indicators $C V_{E t}$ and average $E_{t} / E_{T c}$, both strategies help to carry over soil moisture from wet to dry periods. Indeed, it is interesting to note that well-adapted native vegetation types (i.e. olive groves) are not the ones that maximize water exploitation but are the ones that are able to successfully manage the inter-annual variability of climate. 
The effectiveness of soil moisture storage capacity in improving evapo-transpiration performances helped to assess the suitability of a given species to different landscape conditions (e.g. spatial variability of soil attributes prevalent across the region). Olive, for example, exhibited the smallest minimum allowable value of soil moisture storage capacity among all crops, proving its adaptability to different soil settings (including shallow soils), as exemplified by the exceptional spreading of olives throughout the region. The other crops were shown to be more selective in terms of soil settings as they require larger storage capacities to survive under drought conditions. Thus, the results of the sensitivity analysis are consistent with the observed spatial patterns of vegetation and soil water holding capacity in the study region, enabling to interpret the variability occurring in the Mediterranean landscape in terms of their eco-hydrological controls. This allowed us to consider that, also for agricultural species, despite the strong human disturbances, the water balance behaviour of ecosystems, results to be mainly controlled by natural factors that are not merely climatic but are strongly affected by climate-soil-vegetation interactions. Such a remark is particularly useful since the reduction of uncertainty of water balance models is one of the main research goals particularly in conditions of absence or scarcity of soil-related information. In such a case the respect of eco-hydrological principles may provide useful and non-conventional information which is today mostly not exploited in hydrology.

This kind of pattern interpretation may represent a powerful guide for the development of large scale water balance models in which the critical point of spatial distribution of soil water storage can be effectively constrained from the recognized soil-vegetation affinity patterns.

\section{Appendix A}

\section{Model equations}

Threshold storage and bucket capacity are defined as follows:

$S_{f c}=D_{r} \theta_{f c}$

$S_{w p}=D_{r} \theta_{w p}$

$S_{b c}=D_{r}\left(\theta_{f c}-\theta_{w p}\right)$

Actual evapo-transpiration is modelled according to recommendations by the FAO (UN's Food and Agricultural Organization). Therefore, when the soil moisture is abundant (moisture content is at or above $\theta_{f c}$, or in other words $\left.S(t) \geq S_{f c}\right)$, actual evapo-transpiration is equal to a potential crop evapo-transpiration, $E_{T c}$ of each vegetation type. This procedure involves estimating a reference (i.e. potential) evapo-transpiration $\left(E_{T 0}\right)$ for a "standard crop" through application of the Penman-Monteith equation, and then multiplying it by a crop coefficient $\left(K_{c}\right)$ for the crop in question, thus yielding:

$E_{T}=E_{T c}=K_{c} E_{T 0}$ when $S(t) \geq S_{f c}$

Note that the rate of actual evapo-transpiration $\left(E_{T}\right)$ is estimated for a unit total ground area, with no distinction being made between vegetated and bare soil fractions, with the relative areas of vegetation and bare soil being effectively incorporated within the assumed crop coefficients.

Moreover, Eq. (A4) refers to evapo-transpiration rate under conditions of abundant soil water availability (i.e., a potential rate). However, as the soil moisture decreases, the evapo-transpiration flux is proportionately reduced below this potential rate. The constant of proportionality for nonstandard evapotranspiration (Allen et al., 1998), denoted as the water stress effect $K_{s}(\theta)$, is expressed as a function of the average soil moisture content in the root zone, $\theta$, which is related to the soil moisture storage $S(t)$ through $\theta=S / D_{r}$. The actual evapo-transpiration for a given crop, under waterlimited conditions, is then given by:

$E_{T}=K_{S}(\theta) K_{c} E_{T 0} \quad D_{r} \theta(t)=S(t) \leq S_{f c}$

The function $K_{s}(\theta)$ takes on a value of 1 for $\theta \geq 0.75 \theta_{f c}$, and reduces linearly to zero as the soil water content $\theta$ approaches wilting point $\theta_{w p}$. The functional expression adopted for the water stress coefficient $K_{s}(\theta)$ is reported below in Eq. (A6).

$$
\begin{aligned}
& E_{t}=K_{s}(\theta) K_{c} E_{T o}=\left(\frac{S(t)-S_{w p}}{S_{b c}}\right) K_{c} E_{T o} \text { if } S(t)<0.75 S_{f c} \\
& E_{T}=K_{c} E_{T o} \text { if } S(t) \geq 0.75 S_{f c}
\end{aligned}
$$

Actually, the estimation of $K_{S}(\theta)$ suggest daily water balance computation (Allen et al., 1998), but, as demonstrated from the basic comparison between daily and monthly calculations (see Appendix B), the adopted method to model evapo-transpiration below the potential rate is equally valuable for monthly calculations, at least for the conditions of this study.

Concerning the drainage below the root zone, also referred as soil water yield, the monthly model is based on a pure bucket scheme as in Eq. (A7)

$$
\begin{aligned}
& Y=0 ; \quad \text { if } S(t) \leq S_{f c} \\
& Y=S(t)-S_{f c} \quad \text { if } S(t) \geq S_{f c}
\end{aligned}
$$

\section{Appendix B}

\section{Comparison between monthly and daily model formulation}

Compared with the adopted monthly model, the daily formulation of the soil water balance, regardless of the conceptual 


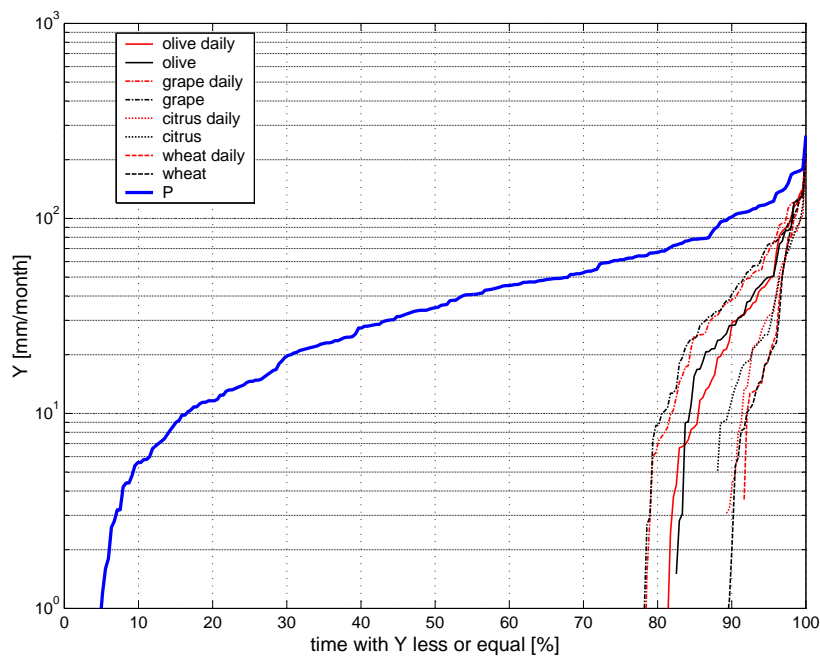

Fig. B1. Comparison between daily and monthly estimation of mean annual water fluxes in response to variable soil moisture storage capacity, $S_{b c}$. Simulations were conducted with soil hydraulic parameter in the typical ranges of the silty-loam. Red marks refer to the daily model while black marks to the monthly one. Drainage response is in the lower part of the figure (decreasing patterns) and evapo-transpiration in the upper part.

flow model, would involve additional soil hydraulic parameters such as, for example, the saturated hydraulic conductivity, the total porosity, the pore size distribution, and the residual water content, that are likely to increase the parametric uncertainty of the model. Therefore, as a proof of the validity of the monthly water balance model results, a daily formulation of the vertical fluxes was also implemented and tested. For the daily predictions of soil water fluxes a Brooks $\&$ Corey formulation was adopted for the un-saturated flow with hydraulic parameters from the literature (Rawls et al., 1992).

All of the results describing the hydrologic response of the Mediterranean landscape at the monthly scale are compared with water balance predictions resulting from a daily model. In order to compare the prediction of the two model formulations hydraulic parameters from silty-loam soils were considered as they cover the widest range of soil water holding capacities among the possible soil textures. The daily predictions of water fluxes were then aggregated at the monthly scale to enable comparison.

Some results of this comparison are reported in Fig. B1 and Fig. B2 concerning both the soil water fluxes at monthly scale and sensitivity of model predictions to variable conditions of soil storage capacity. In particular, Fig. B1 shows the comparison between monthly flow duration curves obtained from the two model formulations in which the differences appear indeed quite limited. The results of the sensitivity analyses of the mean annual soil water balance estimates to variable conditions of soil storage capacity (Fig. B2) appear to be

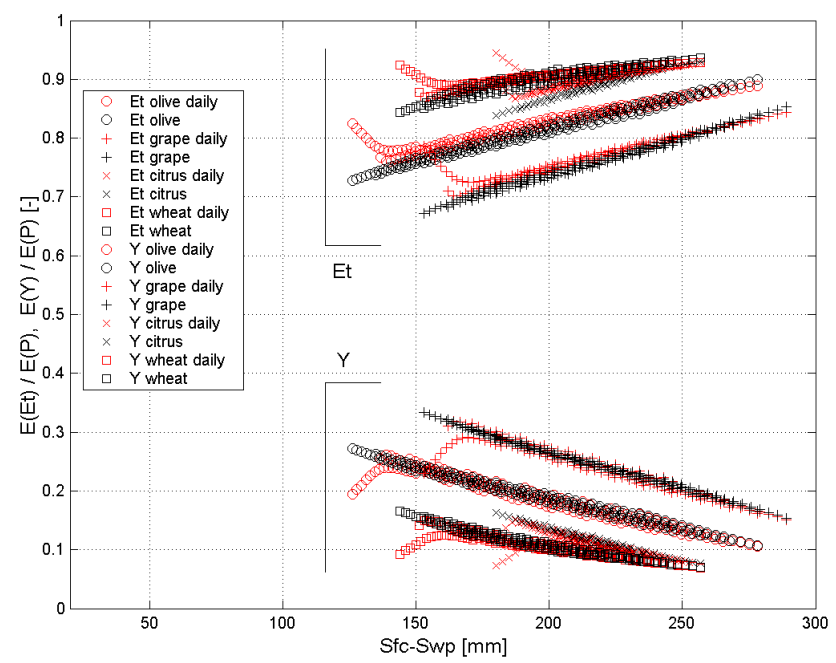

Fig. B2. Comparison between monthly drainage duration curves obtained from the daily (red lines) and monthly (black lines) formulations of the water balance model.

very similar. Probably the negligible differences in the estimation of drainage and evapo-transpiration can be explained by the attenuation of the episodic nature of rainfall caused by the buffering effect of the soil water storage. This attenuation effect is even more evident when the daily calculations are aggregated to months and the typical seasonal pattern is revealed in soil drainage and evapo-transpiration. The comparison between the two water balance models of contrasting complexity, at least for the adopted soil setting, show a consistent agreement for longer time scales as reported by other authors (e.g. Federer, 2003).

Acknowledgements. This work was completed while the senior author (IP) spent a period of study leave at the Centre for Water Research. This study leave was made possible and was supported in part by the Water Research Institute of Italy (Bari). This support is gratefully acknowledged. The authors thank Dr Stan Schymanski for critically reviewing an early version of the manuscript and offering many constructive suggestions.

Edited by: S. Manfreda

\section{References}

Allen, R. G., Pereira, L. S., Raes, D., and Smith, M.: Crop Evapotranspiration, FAO Irrigation and Drainage Paper No. 56, United Nations Food and Agriculture Organization, Rome, Italy, 1998.

Atkinson, S. E., Woods, R. A., and Sivapalan, M.: Climate and landscape controls on model complexity, Water Resour. Res., 38(12), 1314-1330, 2002.

Caliandro, A., Lamaddalena, N., Stelluti, M., and Steduto, P.: ACLA 2 Project - Agro-Ecologic characterization of the Puglia region, CHIEAM IAM-B, 2005. 
Canadell, J., Jackson, R. B., Ehleringer, J. R., Mooney, H. A., Sala, O. E., and Schulze, E.-D.: Maximum rooting depth of vegetation types at the global scale, Oecologia, 108, 583-595, 1996.

Davis, S. D. and Mooney, H. A.: Water use patterns of four cooccurring chaparral shrubs, Oecologia, 70, 172-177, 1986.

Doorenbos, J. and Pruitt, W. O.: Crop Water Requirements. FAO Irrigation and Drainage Paper No. 24, United Nations Food and Agriculture Organization, Rome, Italy, 1977.

Entekhabi, D. and Eagleson, P. S.: Land surface hydrology parameterization for atmospheric General Circulation Models including subgrid scale spatial variability, J. Climate, 2(8), 816-831, 1989.

Farmer, D., Sivapalan, M., and Jothityangkoon, C.: Climate, soil, and vegetation controls upon the variability of water balance in temperate and semiarid landscapes: Downward approach to water balance analysis, Water Resour. Res., 39(2), 1035-1056, 2003.

Feddes, R. A., Hoff, H., Bruen, M., Dawson, T., de Rosnay, P., Dirmeyer, P., Jackson, R. B., Kabat, P., Kleidon, A., Lilly, A., and Pitman, A. J.: Modeling root water uptake in hydrological and climate models, B. Am. Meteorol. Soc., 82, 2797-2809, 2001.

Federer, C. A., Vörösmarty, C., and Fekete, B.: Sensitivity of annual evaporation to soil and root properties in two models of contrasting complexity, J. Hydrometeorol., 4, 1276-1290, 2003.

Finch, J. W.: Estimating direct groundwater recharge using a simple water balance model - sensitivity to land surface parameters, J. Hydrol., 211, 112-125(14), 1998.

Fiorentino, M., Carriero, D., Iacobellis, V., Manfreda, S., and Portoghese, I.: MedCLUB - starting line and first activities, Proceedings of VIIth IAHS Symposium, IAHS (IAHS Red Book Series; PUB: promises and progress - pub. 303), Foz do Iguacu (BR) 04/04/2005-09/04/2005, 463-476, 2006.

Gauch, H. G. and Whittaker, R. H.: Coenocline Simulation, Ecology, 53, 446-451, 1972.
Lepš, J. and Šmilauer, P.: Multivariate Analysis of Ecological Data using CANOCO, Cambridge University Press, ISBN 0521891086, June 2003.

Milly, P. C. D.: Climate, soil water storage, and average annual water balance, Water Resour. Res., 30(7), 2143-2156, 1994.

Rawls, W. J., Ahuja, L. R., and Brakensiek, D. L.: Estimation soil hydraulic properties from soils data, in: Indirect Methods for Estimating the Hydraulic Properties of Unsaturated Soils, Proc. Int. Workshop on Indirect Methods for Estimating the Hydraulic Properties of Unsaturated Soils, edited by: van Genuchten, M. Th, Leij, F. J., and Lund, L. J., Riverside, California, 11-13 October 1989, University of California, Riverside, 1992.

Rodriguez-Iturbe, I., D’Odorico, P., Porporato, A., and Ridolfi, L.: On the spatial and temporal links between vegetation, climate, and soil moisture, Water Resour. Res., 35(12), 3709-3722, 1999.

Santini, A., Coppola, A., Romano, N., and Terribile, F.: Interpretation of the spatial variability of soil hydraulic properties using a land system analysis, in: Modelling of Transport Processes in Soils, edited by: Feyen, J. and Wiyo, K., Wageningen Press, Wageningen, The Netherlands, 491-500, 1999.

Scanlon, T. M. and Albertson, J. D.: Inferred controls on tree/grass composition in a savanna ecosystem: Combining 16-year normalized difference vegetation index data with a dynamic soil moisture model, Water Resour. Res., 39(8), 1224-1237, 2003.

Scholes, R. J. and Walker, B. H.: An Africa Savanna, Cambridge Univ. Press, New York, 1993.

Struthers, I., Hinz, C., Sivapalan, M., Deutschman, G., Beese, F., and Meissner, R.: Modelling the water balance of a free-draining lysimeter using the downward approach, Hydrol. Processes, 17, 2151-2169, doi:10.1002/hyp.1326, 2003.

Zobel, R. W.: Soil environmental constraints to root growth, Adv. Soil Sci., 19, 27-51, 1992. 